\title{
The changes in the research landscape and the revamp of the Journal Motricidade
}

\author{
The challenges and threats researching sports performance
}

Tiago M. Barbosa1*

EDITORIAL | EDITORIAL

The Journal Motricidade (that stands for Motricity in Portuguese) for more than a decade has been publishing original papers and review articles that are methodologically sound, theoretically grounded in the scientific areas of sports sciences, human movement, human development and health. Both qualitative and quantitative researches are welcome. Over this period of time the journal had as mission providing Portuguese speaking researchers a place to share their findings. Journal Motricidade is a niche publication and as such depends strongly of its stakeholders. Therefore, we would like to acknowledge everyone that one way or the other supported this periodic.

However, the research and academia landscape changed over the last ten years. The community has been growing significantly. The amount of research projects funded and papers published has been increasing sharply. Living in a global and interconnected world these days, international collaborations are a must. Because of these opportunities and challenges, it is time to revamp the Journal. Therefore a comprehensive set of changes were put in place. To begin with, we are opening the journal to the international community, besides Portuguese speaking researchers and academics. Hence, submitted manuscripts must be draft in English and comply with the guidelines by the American Psychological Association (APA) for the presentation of scientific articles in peerreviewed journals.

Journal Motricidade will keep providing immediate open access to its content. To allow a quick and effective dissemination of the authors' findings, it is currently indexed in several influential databases. Among these are some of the largest abstract and citation database of peer-reviewed literature such as the ISI Web of Science and Scielo Citation Index by Thomson Reuters, Scopus and EMCare by Elsevier or SCImago (SJR: Medicine, Health Professions). As far as indexing and abstracting goes, we will work towards being included in more databases in the near future.

Submitted manuscripts go through an internal and an external reviewing process. Upon submission by the authors, it is carried out an internal review by the editorial board. The main aim at this stages it to verify if the manuscript falls under the journal's scope, the clarity of the writing, methodological adequacy, if it is in tandem with the best ethical practices and its adherence to the journal's guidelines. If the manuscript fulfils all these criteria, it is forward for blind peer-review.

Another update is that the Journal Motricidade no longer assesses the manuscripts on the subjective perception of importance or novelty of the findings reported. Rather, editors and reviewers are advised to check thoroughly the methodology and how it sounds based on the theoretical background or framework and the state of-the-art on such topic. We are looking forward for a comprehensive and rigorous report of the research design, experiments, data handling and statistical analysis.

\footnotetext{
${ }^{1}$ Editor-in-Chief of the Journal Motricidade; Physical Education \& Sports Science Academic Group, National Institute of Education, Nanyang Technological University

*NIE5-03-31, 1 Nanyang Walk, Singapore; Email: editor.in.chief@revistamotricidade.com
} 


\section{2 | TM Barbosa}

Taking these actions to revamp the publication we hope to increase even more the journal's standards of quality. It is also our wish to be part of the international debate on topics related to sports sciences, human movement, human development and health. If so, we will be helping to build a solid body of knowledge in such areas and; last but not least, to have a meaningful impact on the evidence-based practice by professionals.

c) (7) (8) All content of Journal Motricidade is licensed under Creative Commons, except when otherwise specified and in content retrieved from other bibliographic sources. 